\title{
Experience of Major Limb Amputations in a Tertiary Care Hospital
}

\author{
Mir Tariq ${ }^{1}, D O, D N B ;$ Aakash Pandita ${ }^{2}$, MD; Muhammad Haseeb ${ }^{1}$, MS; Varun \\ Narula ${ }^{1}$,DNB; Deepak Sharma ${ }^{3}$, MD; Dr Smita Pawar ${ }^{4}$, DNB; Dr Avinash Kaul ${ }^{5}$, MS. \\ ${ }^{1}$ Department of Orthopaedics, KDA Hospital Mumbai. \\ ${ }^{2}$ Department of Paediatrics, Government Medical College and Hospital, Jammu. \\ aakash.pandita@gmail.com \\ ${ }^{3}$ Deptt of Orthopaefics, GMC Jammu. \\ ${ }^{4}$ Department of OBG, Fernandez Hospital ,Hyderabad. \\ ${ }^{5}$ Department of Surgery, ASCOMS, Jammu.
}

\begin{abstract}
:
Objectives: To determine the pattern and causes of major limb amputations at a tertiary care hospital.

Study design: Case series

Methods: Inpatient case sheets of patients who underwent major limb amputations from July 2011 to June 2012 in the department of orthopaedic its wear included in the study. Patient's age, gender, pattern and cause of amputation, and complications were studied.

Results: Total 80 patients had major limb amputation with a mean age of $44.7( \pm 18.8)$ years. Severe trauma $(30 \%)$ was the most common cause of amputation followed by peripheral vascular disease (26.3\%) and diabetic gangrene (20\%). Additional procedures in the form of debridement and skin grafting were needed to tackle post-operative wound infection(75\%), wound dehiscence(16.7\%) and stump necrosis(5.6\%). 1 (2.7\%) patient died of disseminated clostridial infection during hospital stay even after amputation. Hospital stay ranged from 6 days to 28 days with an average stay of 15.4 days.

Interpretation and conclusions: Trauma followed by peripheral vascular diseases and diabetic gangrene were the common causes of amputation in our settings. The study shows that most of the causes are potentially avoidable. Community health education programmes focussing on road safety measures, early presentation to the physician and good diabetic control are pivotal to decrease the incidence of amputations for preventable indications.
\end{abstract}

Keywords: Diabetes mellitus, Limb amputations, peripheral vascular disease, trauma

\section{INTRODUCTION}

Amputation is the removal of whole or part of the limb. Lower extremity amputation is the most common amputation surgery. A major amputation is one that is performed proximal to wrist or ankle. Limb amputation can be considered as both a life-saving procedure and a life changing event. Individual responses to amputation vary and are influenced by a range of social, clinical, personal, physical and environmental factors.

Amputation surgery is an ancient procedure dating back to prehistoric times. Inscribed on black stone; from $1700 \mathrm{BCE}$, Babylonian code of Hammurabi is the earliest literature discussing amputation. ${ }^{8}$ It was Hippocrates (460-377 BC) who made the first surgical description of amputation. The worldwide incidence of amputation is unknown. There are geographical variations in the prevalence. Indications for amputation also vary within and between countries, but common indications are peripheral vascular diseases, trauma, infections, complications of diabetes mellitus and tumors. Our study aimed to determine the pattern, causes and complications of major limb amputations at a tertiary care centre in a developing country.

\section{Methodology}

This was a case series of amputations done in a tertiary care hospital in a developing country. Case sheets of patients who underwent major limb amputations within the study period from July 2011 to 
June 2012 were examined. Data collection focussed on patient's age, gender, affected extremity, and indication for amputation, level of amputation and post-operative complications. Approval from institutional ethics board was sought for the study.

\section{ReSUlts}

There were 80 patients who underwent major limb amputations comprising 59 (73.7\%) males and $21(26.3 \%)$ females with a male: female ratio of 2.8:1. Age distribution is given in table.1

Table1. Age Distribution

\begin{tabular}{|l|l|l|}
\hline Age (years) & Number & Percentage (\%) \\
\hline $0-15$ & 4 & 5 \\
\hline $16-30$ & 14 & 17.5 \\
\hline $31-45$ & 24 & 30 \\
\hline$>45$ & 38 & 47.5 \\
\hline Total & $\mathbf{8 0}$ & $\mathbf{1 0 0}$ \\
\hline
\end{tabular}

The mean age ( \pm standard deviation) was $44.7( \pm 18.8)$ years. The commonest cause was trauma (30\%) followed by peripheral vascular disease $(26.3 \%)$ and diabetic gangrene $(20 \%)$. Indications of amputations are mentioned in table. 2

Table2. Indications for Amputation

\begin{tabular}{|l|l|l|}
\hline Indications & Number & Percentage (\%) \\
\hline Severe trauma & 24 & 30 \\
\hline Vascular disease & 21 & 26.3 \\
\hline Diabetic gangrene & 16 & 20 \\
\hline Tumors & 7 & 8.7 \\
\hline Burns & 4 & 5 \\
\hline Chronic osteomyelitis & 3 & 3.7 \\
\hline Traditional bone setter gangrene & 3 & 3.7 \\
\hline Necrotising fasciitis & 1 & 1.3 \\
\hline Gas gangrene & 1 & 1.3 \\
\hline Total & $\mathbf{8 0}$ & $\mathbf{1 0 0}$ \\
\hline
\end{tabular}

There were 57 (71.3\%) lower extremity amputations and 23 (28.7\%) upper extremity amputations. Levels of amputation with their frequency are mentioned in table. 3

Table3. Levels of Amputation

\begin{tabular}{|l|l|l|}
\hline Level & Frequency & Percentage (\%) \\
\hline Above knee & 23 & 28.7 \\
\hline Below knee & 34 & 42.5 \\
\hline Shoulder disarticulation & 2 & 2.5 \\
\hline Above elbow & 8 & 10 \\
\hline Below elbow & 13 & 16.3 \\
\hline Total & $\mathbf{8 0}$ & $\mathbf{1 0 0}$ \\
\hline
\end{tabular}

Post-operatively 36 (45\%) patients had complications (table.4)

Table4. Post-operative complications

\begin{tabular}{|l|l|l|}
\hline Complications & Frequency & Percentage (\%) \\
\hline Wound infection & 27 & 75 \\
\hline Wound dehiscence & 6 & 16.7 \\
\hline Stump necrosis & 2 & 5.6 \\
\hline Death & 1 & 2.7 \\
\hline
\end{tabular}

consisting of wound infection in $27(75 \%)$, wound dehiscence in 6(16.7\%) and stump necrosis in $2(5.6 \%)$ which required additional procedures in the form of debridement and split skin grafting. $1(2.7 \%)$ person died of progressive gas gangrene despite emergent amputation. Hospital stay of the 
patients ranged from 6 days to 28 days with an average stay of 15.4 days. 42 amputations involved the right side extremity, 33 involved left side extremity and 5 amputations were bilateral.

\section{DisCuSSION}

Amputation is one of the oldest surgical procedures. Limb amputation should not be considered as a failure of treatment. Rather, it can be a life saving procedure in some cases. Amputation has a significant impact on the life of patient after amputation with lower limb amputees experiencing more changes in their life compared to upper limb amputees. ${ }^{2}$ Also, the incidence varies in the two groups with higher incidence in the lower limb amputees. ${ }^{3}$

In India, sufficient data regarding the overall incidence and etiological background of major limb amputations is not available. As per the data from 2006 by World Health Organisation, India has the highest number of road accidents in the world with 16.8 fatal injuries per 100,000 population and 38.9 non-fatal injuries per 100,000 population. ${ }^{4}$ From this data, it can be presumed that road traffic accidents would be a significant cause of limb amputations. ${ }^{5}$ Our results are in agreement with this data as trauma was responsible for $30 \%$ of amputations in our study. However, in our study this indication may be over-documented as we included cases of rail road accidents, industrial accidents, crush injuries due to stone slides in hilly areas and most notably crushed upper extremity due to grass cutting machine injuries in patients from villages.

Peripheral vascular disease (PVD) unrelated to diabetes was the second common indication of amputation in our study. PVD has been seen as the most common indication for amputation in developed countries. ${ }^{7,9}$ In our settings, such a result can be related to late presentation of patients to the physician when extensive gangrene has occurred, and revascularisation and limb salvage is not a feasible option. Most of our patients belonged to the far flung areas and had no formal education. Also, this changing pattern of indications for amputations in developing countries points towards the emergence of PVDs and diabetes as the major public health problems owing to the changing life styles, and need for preventive measures to avoid such complications.

Complication of diabetes mellitus was the third most common indication for major limb amputation in our study, which is not in agreement with other similar studies. ${ }^{6}$ All the amputations involved lower extremity; showing diabetic gangrene is more common in lower limb than anywhere else in the body. Similar trend was also reported in other series. ${ }^{1}$ As per the estimates of the World Diabetes Foundation; about 40,000 lower limb amputations are performed each year in India due to diabetic complications. ${ }^{3}$

Amputations for electric burn injuries involved the upper extremity as did amputations for gangrene after manipulation by traditional bone setter in our study. Despite having a traumatic origin, separate mention of gangrene after manipulation by bone setter was made to stress the role of community awareness against these practices which are still so common in our part of world.

Postoperatively, immediate complication rate in our study was $45 \%$, commonest being the surgical site infection. Other complications of wound dehiscence and stump necrosis were seen. These complications had an impact on cost of amputation by increasing the hospital stay. As most of the amputations were performed in accident and emergency, inadequate asepsis may well be the cause of increasing postoperative surgical site infection rates in our setup. Also as majority of amputations were performed by postgraduate trainees, issues of surgical skill can have a role in high proportion of such complications. Compromised immunity in cases of diabetes and PVD can also account for such complications in early postoperative period. However, future long term prospective studies are warranted. These complications were dealt with procedures like debridement and skin grafting.One patient who had amputation for gas gangrene died of disseminated infection despite emergent amputation.

\section{CONClusion}

Trauma, peripheral vascular diseases and diabetic gangrene were the most common indications for amputation in our settings. Majority of these indications are preventable through provision of safety measures for road traffic accidents, community health education to encourage early presentation to the hospital and good diabetic control. 


\section{REFERENCES}

[1] Chalya PL, Mabula JB, Dass RM, Kabangila R, Jaka H, Mchembe DM, Kataraihya JB, Mbelenge N, Gilyoma JM: Surgical management of Diabetic foot ulcers: A Tanzanian university teaching hospital experience. BMC Research Notes 2011;4:365

[2] Demet K, Martinet N, Guillemin F, Paysant J, Andre J-M. Health related quality of life and related factors in 539 persons with amputation of upper and lower limb. Disabil Rehabil 2003;25(9):480-6

[3] Diabetes foot care: step-by-step. Available from: URL: http://www.worlddiabetesfoundation.org/ projects/indiaTanzania-WDF03-056.

[4] Global status report on road safety. World Health Organisation 2009.

[5] Mansoor I, Margoob MA, Masoodi N, Mushtaq H, Younis T, Hussain A et al. Prevalence of psychiatric comorbidities in traumatic amputees: A cross sectional study from Kashmir (Indian part). Br J Med Pract 2010;3(4):347

[6] Masood J, Irfan A, Ghulam M: Current indications for major lower limb amputation. Pakistan J. Surg 2008;24(4):228-231

[7] Pernot HF, Winnubst GM, Cluitmans JJ, De Witte LP. Amputees in Limburg: Incidence, morbidity and mortality, prosthetic supply, care utilisation and functional level after one year. Prosthet Orthot Int 2000;24:90-6

[8] Robinson KP. Historical aspects of amputation. Ann Roy Coll Surg Engl. 1991;73:134-36

[9] Rommers GM, Vos LD, Groothoff JW, Schuiling CH, Eisma WH. Epidemiology of lower limb amputees in the north of the Netherlands: aetiology, discharge destination and prosthetic use. Prosthet Orthot Int 1997;21:92-9

[10] Ziegler-Graham K, MacKenzie EJ, Ephraim PL, Travison TG, Brookmeyer R. Estimating the prevalence of limb loss in the united states:2005 to 2050. Arch Phys Med Rehabil 2008;89(3):422-9 